\title{
Configurações
}

Revista de sociologia

\section{Os ciganos de Lisboa e a escolarização: evoluções,} impasses, dilemas (2003-2015)

The Lisbon Gypsies and schooling: developments, impasses, dilemmas

(2003-2015).

Les tisganes de Lisbonne et la scolarisation: évolutions, blocages, inquiétudes

(2003-2015)

\section{Daniel Seabra Lopes e Ana Rita Costa}

\section{(2) OpenEdition}

\section{Journals}

Edição electrónica

URL: http://journals.openedition.org/configuracoes/3652

DOI: $10.4000 /$ configuracoes.3652

ISSN: 2182-7419

\section{Editora}

Centro de Investigação em Ciências Sociais

Edição impressa

Paginação: 67-86

ISSN: 1646-5075

\section{Refêrencia eletrónica}

Daniel Seabra Lopes e Ana Rita Costa, « Os ciganos de Lisboa e a escolarização: evoluções, impasses, dilemas (2003-2015) », Configurações [Online], 18 | 2016, posto online no dia 30 dezembro 2016, consultado o 20 abril 2019. URL : http://journals.openedition.org/configuracoes/3652 ; DOI : 10.4000/ configuracoes.3652 
Lopes, Daniel Seabra; Costa, Ana Rita - 0s ciganos de Lisboa e a escolarização: evoluções, impasses, dilemas (2003-2015) Configurações, vol. 18, 2016, pp. 67-86

\section{Os ciganos de Lisboa e a escolarização: evoluções, impasses, dilemas (2003-2015)}

DANIEL SEABRA LOPES*

Universidade Lisboa

ANA RITA COSTA**

Instituto Universitário de Lisboa

\section{Resumo}

O presente artigo debruça-se sobre a relação dos ciganos com a escola, tomando como exemplo a população residente num bairro de Lisboa em dois momentos distintos, cada um deles correspondendo à realização de um trabalho de campo: 2003-2005 e 2014-2015. A informação empírica decorrente destas investigações permite afirmar que os ciganos de Lisboa valorizam uma certa aproximação e integração no mundo não-cigano que os rodeia, incluindo o universo educativo, o que os torna naturalmente recetivos a determinadas medidas de combate ao insucesso escolar. Ao mesmo tempo, a escola coloca desafios importantes a esta população: alguns destes desafios mexem com a performação da identidade cigana, enquanto outros decorrem da escassez de condições de ensino que lhe são oferecidas pelos não-ciganos. Numa tal situação, torna-se particularmente importante compreender a posição destas comunidades face à integração para, a partir daí, construir um caminho comum fundado no diálogo em vez de na imposição. Um tal desiderato nem sempre é fácil de conciliar com as políticas sociais, de educação e emprego, daí que a impressão mais marcante acerca do período temporal aqui em causa seja de estagnação.

Palavras-chave: ciganos; Integração; Políticas Educativas; Etnografia; Lisboa.

*Daniel Seabra Lopes (CSG-ISEG, Universidade de Lisboa): danielslopes@iseg.ulisboa.pt

**Ana Rita Costa (ISCTE-Instituto Universitário de Lisboa): ana.rita.costa@iscte.pt 


\begin{abstract}
The Lisbon Gypsies and schooling: Developments, Impasses, Dilemmas (2003-2015) This article focuses on the relationship of the gypsies (ciganos) with the school, taking as an example the resident population in a quarter of Lisbon in two distinct moments, each corresponding to the completion of different fieldworks: 2003-2005 and 20142015. The empirical information arising from these investigations suggests that Lisbon gypsies value a certain proximity and integration in the non-gypsy environment around them, including the educational universe, which makes them naturally receptive to certain policy measures against school failure. At the same time, the school poses significant challenges to this population: some of these challenges have to do with the performance of the gypsy identity, while other stem from the lack of educational conditions that are offered. In such a situation, it is particularly important to understand the position of these communities regarding integration and, on this basis, build a common path founded on dialogue rather than imposition. Such a project is not always easy to achieve in practice regarding social, educational and job policies, and that is why the most striking impression about the time period in question is one of stagnation.
\end{abstract}

Keywords: gypsies (Ciganos);Integration; Educational Policies; Ethnography;Lisbon.

\title{
Résumé
}

Les tisganes de Lisbonne et la scolarisation: évolutions, blocages, inquiétudes (2003-2015)

Cet article porte sur la relation des Roms (tsiganes) avec l'école, en prenant pour exemple la population résidant dans un quartier de Lisbonne lors de deux moments distincts, chacun correspondant à un travail de terrain : 2003-2005 et 2014-2015. Les informations empiriques découlant de ces recherches suggèrent une certaine approximation et intégration des tsiganes de Lisbonne dans le monde non-tsigane autour d'eux, y compris l'univers éducatif, ce qui les rend naturellement réceptifs à certaines mesures de lutte contre l'échec scolaire. Parallèlement, l'école confronte cette population à des défis importants : certains de ceux-ci concernent la préformation de l'identité tsigane, tandis que d'autres résultent de l'absence de conditions d'enseignement mises à disposition des tsiganes. Dans une telle situation, il est particulièrement important de comprendre la position de ces communautés face à l'intégration pour construire un chemin commun fondé sur le dialogue plutôt que sur l'imposition. Un tel objectif n'est pas toujours facile à concilier avec les politiques sociales, d'éducation ou d'emploi, raison par laquelle l'impression la plus marquante de cette période est celle de la stagnation.

Mots-clés:tsiganes; Intégration; Politiques d'éducation; Ethnographie; Lisbonne. 


\section{Introdução: a dupla face da integração dos ciganos}

Se o reconhecimento e a integração de grupos minoritários desfavorecidos são objetivos que não oferecem qualquer discussão num estado de direito democrático (Comissão Europeia, 2010; Council of Europe 2012; Parlamento Europeu, 2012; Estratégia Nacional..., 2013), reparamos no entanto que eles levantam questões delicadas quando se passa da teoria para a prática, do geral para o particular, do abstrato para o concreto. No que diz respeito aos ciganos, aliás como a qualquer grupo etnicamente marcado, podemos dizer que existem duas visões acerca da integração: uma visão cigana, minoritária e dominada, mas que é sentida a partir de dentro, estando bastante arreigada nas práticas quotidianas, nas aspirações individuais e coletivas, no carácter e nos corpos das pessoas; e uma visão não-cigana (identificável com aqueles que os ciganos tratam, sem qualquer sentido elogioso, por senhores ou doutores), maioritária e dominante, suscetível de se traduzir em posições institucionais paternalistas e discriminatórias. Como facilmente se percebe, a coincidência entre as duas visões, não sendo impossível, está longe de ser um dado imediato. E o facto de estarmos perante uma relação desigual faz com que a visão não-cigana tenda a imperar — frequentemente alicerçada na ideia de que os passos para a integração têm de ser dados "de parte a parte" —, ainda que com resultados muitas vezes insatisfatórios. Valeria a pena, por isso, fazer um esforço de aproximação ao outro e tentar perceber como é que os ciganos veem hoje a questão da integração, para depois se refletir sobre a melhor maneira de promover o encontro de vontades.

O presente artigo propõe-se analisar a situação de uma comunidade cigana lisboeta face às instituições não-ciganas e, em particular, face à escola. Servimo-nos da expressão 'comunidade' para designar um conjunto variável de pessoas unidas por uma atenção e uma sensibilidade face a determinado tipo de problemas, circunstância que gera um efeito de reconhecimento e cumplicidade entre os seus membros, e um sentimento distância face aos que estão de fora. Assim entendida, uma comunidade cigana é mais do que uma simples família (mesmo alargada), aproximando-se daquilo que (Appadurai 1996: 178-188) entende como 'vizinhança'. Os dados empíricos que sustentam a nossa reflexão provêm de um trabalho de campo de longa duração efetuado por Daniel Seabra Lopes entre 2003 e 2005 e que serviu de base a uma etnografia abrangente, atenta a aspetos de natureza social, cultural, económica, política e simbólica (vide Lopes, 2008; 2013). Estes dados mais antigos são aqui complementados com os dados recolhidos por Ana Rita Costa entre 2014 e 2015, no mesmo terreno e ainda noutros dois bairros da periferia de Lisboa, no âmbito do projeto Fatores-chave para o Sucesso e a Continuidade dos Percursos Escolares dos Ciganos: Indivíduos, Famílias e Políticas Públicas. De enfoque mais preciso, este projeto envolveu ainda trabalho de campo etnográfico em contexto escolar, nomeadamente em duas escolas de um dos Agrupamentos que serve o bairro 
em questão, a realização de catorze entrevistas a pessoas ciganas do mesmo bairro (homens e mulheres com diferentes idades e níveis de escolaridade) e a dinamização de dois grupos focais, o primeiro envolvendo três homens e três mulheres ciganas e o segundo três professores e uma assistente social que trabalhava no território há mais de duas décadas.

Ora, a conjugação da informação empírica decorrente destas investigações permite afirmar, sem qualquer dúvida, que os ciganos de Lisboa valorizam uma certa aproximação e integração no mundo não-cigano que os rodeia - incluindo o universo escolar. Seria, de resto, muito estranho se assim não fosse. Boa parte das etnografias efetuadas junto de populações reconhecidas como ciganas revelam o mesmo interesse de inclusão parcial (Ardèvol, 1986; Blasco, 1999), ainda que as diferenças de contexto nos impeçam de entrar em generalizações abusivas. Isto deve ser reconhecido, inclusivamente, contra certas perspectivas antropológicas que acabam por encapsular os ciganos numa marginalidade recorrente, vendo, por exemplo, na sua resistência à escolarização um sinal de vitalidade ainda mais significativo que a resistência à sedentarização (Gmelch, 1986: 325; Pasqualino, 1999: 619). Mas a escola coloca, como iremos ver, desafios importantes aos ciganos de Lisboa. Alguns destes desafios mexem com a performação daquilo que é localmente entendido como a identidade cigana, enquanto outros decorrem da escassez de condições oferecidas pelo sistema público de ensino (e seus parceiros), numa conjuntura de desinvestimento na educação e declínio das políticas sociais de amparo em favor de medidas com caráter punitivo.

Ainda uma palavra a respeito do contexto primordial deste estudo. Trata-se, como já demos a entender, de um bairro lisboeta habitado por diversas famílias ciganas, algumas das quais aí instaladas há mais de quatro décadas. A maioria destas famílias residiam em apartamentos arrendados em dois blocos de habitação social inaugurados no início do século e quase exclusivamente ocupados por ciganos, estando as restantes famílias disseminadas por um conjunto de prédios mais antigos. Ao todo, estaremos a falar de cerca de trezentos indivíduos ciganos numa área da cidade que combina aspetos característicos dos bairros sociais com infraestruturas importantes (por exemplo, um polo universitário) e monumentos históricos que atraem alguns turistas. Embora a duração da presença cigana na zona se tenha traduzido em diversas relações de convivialidade e entreajuda com os seus vizinhos nãociganos, verificava-se uma certa segregação que também se refletia em termos da distribuição territorial. Outro pormenor importante tem a ver com o facto de uma parte considerável destas famílias usufruir das prestações do Rendimento Mínimo Garantido (atual Rendimento Social de Inserção) — uma medida de proteção social introduzida em 1996 e que veio beneficiar muitas pessoas de meios desfavorecidos, na sua maioria não-ciganas. Mas as prestações sociais do Rendimento Social de Inserção, ainda que regulares, eram insuficientes 
e suscetíveis de ser retiradas em caso de incumprimento, não dispensando o recurso aos ganhos incertos do exercício da venda ambulante e de pequenos biscates.

Este quadro será desenvolvido ao longo das páginas que se seguem. A próxima secção considera a relação dos ciganos com a escola no período 2003-2005. A terceira secção do artigo aprecia a relação mantida com outros domínios da esfera institucional não-cigana, nomeadamente o emprego e a saúde, identificando pontos de adesão e resistência. A quarta secção oferece um panorama da situação atual incidindo sobretudo na situação escolar dos ciganos, procurando perceber se alguma coisa mudou e porquê. A quinta secção complementa este panorama com uma breve excursão sobre o acesso ao emprego por parte dos ciganos e a outras estratégias de subsistência. A sexta secção conclui, inserindo os dados do nosso contexto etnográfico no âmbito de políticas nacionais e posicionamentos no terreno que se afiguram persistentes.

\section{Os ciganos de Lisboa e a escolarização (2003-2005)}

São vários os estudos que dão conta da baixa escolarização e abandono precoce entre as comunidades ciganas de Portugal concentradas em bairros sociais, aglomerados de barracas ou acampamentos, sobretudo quando comparadas com os números da população nacional (Casa-Nova, 2009: 179-180; Nicolau, 2010; 2013). O estudo nacional levado a cabo por Manuela Mendes, Olga Magano e Pedro Candeias (2014) comprovou esta impressão, alertando porém para a influência de determinadas políticas sociais no aumento da frequência escolar e dos níveis de escolaridade dos ciganos a partir dos anos 1990 (vide também Gomes, 2013) — de resto à semelhança da restante população portuguesa, ainda que permanecendo muito aquém desta.

No bairro lisboeta aqui em causa, o cenário em 2003 era, a vários níveis, previsível. Para um universo que então se aproximava dos quatrocentos indivíduos ciganos, mais de metade não tinha qualquer nível de ensino, cerca de sessenta tinham completado o primeiro ciclo, havendo apenas trinta com o segundo ciclo e não mais que quatro ou cinco com o terceiro ciclo (Lopes, 2008: 53-55). Mesmo admitindo que uma parte importante desta população era composta por crianças com menos de seis anos (aliás assíduas frequentadoras de creches e jardins-de-infância, como iremos ver...), e havendo ainda uma percentagem de dezoito por cento cujas habilitações eram desconhecidas, a verdade é que estes números contrastavam significativamente com os da população da Grande Lisboa, onde quase quarenta por cento dos residentes tinha o nono ano (terceiro ciclo) ou mais.

O trabalho de campo realizado permitiu, naturalmente, compreender as razões que explicavam este cenário. Parte destas razões fundavam-se no 
ponto de vista cigano sobre a escola, tendo em conta a chamada lei cigana e outros preceitos normativos que, longe de estarem fundados numa cultura ancestral e imutável, exigiam uma constante performação a nível local: todos os dias, no bairro, os ciganos tinham de emitir determinados sinais de pertença étnica reconhecíveis pelos seus pares, entre os quais se contava uma determinada reserva quanto à frequência de espaços não-públicos controlados pelos senhores - como era o caso dos recintos escolares. Mas as condições oferecidas pelo complexo institucional envolvente também contribuíam para aumentar o desinteresse e o afastamento dos ciganos em relação à escola. O problema, recordemo-lo, tem sempre duas faces. Olhemos agora, mais em detalhe, para cada uma delas...

Podemos afirmar que a escola era encarada com circunspeção pela maior parte dos ciganos, o que reenviava para questões de identidade associadas à centralidade do casamento no ciclo de vida, à valorização da virgindade feminina pré-nupcial e, de um modo mais lato, à separação dos géneros no espaço público e no espaço institucional não-cigano. Sucede que a escola, ao contrário de outros ambientes institucionais como o hospital ou a prisão, deixou há muito de estabelecer fronteiras espaciais segundo o género, permitindo hoje que rapazes e raparigas interajam normalmente uns com os outros tanto nas salas de aula como no recreio. Tendo em conta que a possibilidade de casamento se coloca, para os ciganos, assim que se atinge a puberdade, e que a noiva ideal se deve manter virgem (honrada) até ao matrimónio, torna-se importante velar pela reputação das raparigas e evitar qualquer suspeição de contactos menos próprios com rapazes. Num meio fortemente permeado pela oralidade como este, onde as histórias de condutas menos próprias circulam rapidamente e ganham um estatuto de verdade também pela emoção que provocam, muitos familiares são levados a restringir a mobilidade das raparigas de modo a que a sua reputação permaneça incólume e as possibilidades de casamento sejam ampliadas. Estas preocupações foram-nos descritas de forma eloquente por um pastor evangélico de 45 anos que conhecemos numa festa de casamento em 2004, para quem a promiscuidade do ambiente escolar se afigurava um sério obstáculo à própria continuidade dos ciganos:

Nós não podemos pôr as nossas filhas na escola, porque senão aí acaba tudo! No dia em que as nossas filhas puderem ir à escola, pronto, acabam-se os ciganos! No dia em que as nossas mulheres deixarem de ser honradas, o que é que fica dos ciganos? E os rapazes também não podem ir à escola! Se eles vão à escola e depois têm estudos, como é que vão querer casar com uma cigana que não sabe nada? Não, eles querem é ficar com outras!

Embora se esteja a falar, no fundo, de uma identidade que se vai reproduzindo quotidianamente e, por isso mesmo, também transformando 
e reinventando ao sabor das expressões, dos gestos e das curiosidades individuais, é relativamente comum que ela seja apresentada como uma marca mais fixa e, até certo ponto, inconciliável com tudo o que lhe seja exterior. Evidentemente, não consideramos que a escola - incluindo a educação superior - seja antitética com a manutenção da identidade cigana, como aliás tem vindo a ser demonstrado por alguns estudos (Abajo e Carrasco, 2004; Brüggemann, 2014; Higgins e Brüggemann, 2014). De qualquer modo, mesmo em contextos onde ela seja sentida como potencialmente ameaçadora, a escola também não pode ser simplesmente ignorada pelos ciganos que não a queiram frequentar. No bairro aqui em causa, a obrigação da frequência escolar incidia tanto sobre os menores de idade como sobre os adultos e era, antes de mais, ditada pelo próprio Rendimento Social de Inserção, que geralmente propunha a assiduidade e o bom aproveitamento nas aulas como contrapartida a todos os beneficiários que não tivessem as habilitações escolares mínimas. A aquisição de competências literárias e de outros conhecimentos era igualmente muito valorizada pelos técnicos e assistentes sociais que interagiam quotidianamente com esta população, considerando-a um ingrediente indispensável em termos de integração social e pleno exercício da cidadania. O encaminhamento escolar era ainda reforçado pela intervenção de três mediadores ciganos com ligações familiares na zona, incumbidos da missão de chamar a atenção dos pais para a importância da frequência e assiduidade escolar dos seus filhos.

Como tal, quase todas as crianças ciganas do bairro se encontravam inscritas nas escolas - o que provavelmente constituiria um avanço face a tempos mais recuados -, embora o absentismo e o insucesso escolar fossem elevados sobretudo a partir do segundo ciclo, e tanto entre os rapazes como entre as raparigas. Da mesma forma, todos os adultos titulares ou beneficiários do Rendimento Social de Inserção cujas habilitações estivessem abaixo do nível de ensino obrigatório (nessa altura, o nono ano) tinham de se comprometer com um programa de formação escolar, sob pena de perderem o direito à prestação. Isto fazia com que muitos ciganos vissem a frequência escolar apenas como uma "obrigação» necessária para se continuar a receber o dinheiro da prestação social.

Acresce que as condições oferecidas pelas escolas do bairro também não eram de molde a atrair os ciganos: para além dos horários rígidos e da focalização numa única autoridade lectiva (o professor) - o que contrasta com os regimes de aprendizagem mais improvisados e distribuídos que vigoravam nesta comunidade - , as turmas tinham demasiados alunos, fazendo com que muitas aulas se resumissem a tentativas de controlo da indisciplina. As questões da cultura e identidade ciganas estavam completamente ausentes dos manuais e a introdução dos mediadores ciganos era bastante recente e ainda mal compreendida. No caso do Ensino Recorrente de primeiro ciclo (programa destinado a adultos sem qualquer nível de ensino e, neste caso, frequentado 
tanto por homens como mulheres), o panorama era ainda mais desolador: as aulas começavam já o ano letivo ia adiantado, eram ministradas nas instalações de uma escola primária por professores pouco motivados e que se limitavam a seguir o programa geral, havendo apenas com um horário disponível - ao fim da tarde, coincidindo com as tarefas femininas de preparação do jantar. Não sendo, evidentemente, caso único, estas razões oriundas do mundo dos senhores concorriam para acentuar a distância entre os ciganos e a escola.

Saliente-se mesmo assim que, no tocante à educação pré-escolar, a adesão dos ciganos foi rápida e tranquila. À semelhança do que sucedeu com a inscrição nos centros de saúde, de que falaremos a seguir, a inscrição de crianças ciganas em estabelecimentos pré-escolares foi largamente uma consequência da implementação do Rendimento Social de Inserção. Antes disso, a maioria das crianças permanecia junto dos familiares. Mas assim que os ciganos se asseguraram de que as creches e jardins-de-infância eram locais acolhedores, onde os seus filhos mais novos eram bem tratados, não tiveram qualquer problema em matriculá-los aí, inclusivamente sem necessidade do acompanhamento dos técnicos e tomando eles próprios a iniciativa de assegurar vagas naqueles equipamentos que ofereciam melhores condições. Um exemplo que consideramos demonstrativo do que significa uma procura da escolarização por parte dos ciganos sem que transpareça qualquer tensão face aos preceitos da lei cigana nem o peso de uma qualquer contrapartida imposta pelos não-ciganos - e que vale a pena ter em mente nas páginas que se seguem.

\section{Outros cenários: emprego, medicalização e encarceramento}

Sendo a inserção no mercado de trabalho uma preocupação tipicamente nãocigana e que é entendida, cada vez mais, como uma consequência do percurso escolar, não é de admirar que a situação profissional dos ciganos do bairro lisboeta aqui em causa refletisse o seu percurso educativo e se apresentasse, aos olhos dos senhores, como igualmente desoladora ou — na melhor das hipóteses - como bastante intermitente. Embora muitos indivíduos estivessem inscritos no Centro de Emprego da área (como aliás era especialmente recomendado aos beneficiários do Rendimento Social de Inserção em idade adulta e com um mínimo de habilitações escolares), raramente eles eram convocados para qualquer entrevista de emprego devido às suas baixas qualificações. E quando acontecia que um cigano ou cigana fossem chamados para desempenhar serviços de limpeza ou outras tarefas que não requeriam quaisquer habilitações, pouco tempo se aguentavam no local de trabalho. Isto era sobretudo devido à precariedade dos vínculos laborais (exacerbada pelo racismo de alguns empregadores que, segundo se contava, dispensavam os seus colaboradores assim que se apercebiam da sua filiação étnica), a que podia aliar-se algum 
desinteresse da parte dos próprios ciganos quanto à permanência prolongada num mesmo emprego.

Saliente-se que trabalhar por conta de outrem numa fábrica ou empresa - sujeito a horários rígidos, a hierarquias institucionais, a regras que impõem um afastamento da comunidade de referência durante uma boa parte do dia — não era propriamente um objetivo genuinamente almejado pela maior parte dos ciganos deste bairro. $\mathrm{O}$ recurso a biscates nas áreas da construção civil, oficina mecânica ou mudanças era pontualmente praticado mas também escamoteado pelos homens mais velhos, precisamente por não ser consentâneo com a manutenção de uma identidade cigana ainda muito marcada pela convivialidade endógena. Porém, certos empregos duradouros no campo da segurança eram bem aceites pelos homens, nomeadamente por implicarem maior flexibilidade de horários. No tocante às mulheres, aplicava-se o mesmo tipo de cuidados suscitados pela frequência escolar após a puberdade: a sua ausência durante boa parte do dia para desempenhar funções numa instituição potencialmente promíscua poderia pôr em causa, aos olhos dos familiares e vizinhos ciganos, a moralidade da sua conduta - aspeto que chegou a ser reconhecido pela Comissão Nacional do Rendimento Mínimo (2002: 48).

Em compensação, no caso dos jovens adultos do sexo masculino, o trabalho pontual por conta de outrem parecia menos 'poluidor' em termos de identidade: os rapazes aderiam a ele sem grandes angústias, vendo nisso uma forma de acumularem algum dinheiro sem se comprometerem com um emprego estável. Sucedia que a falta de habilitações e os preconceitos racistas dos empregadores tornavam este expediente muito incerto. Por outro lado, a formação profissional ao dispor da população mais jovem era reduzida (cursos de carpintaria e informática para rapazes, de corte e confeção, ponto-cruz e dança flamenca para raparigas e de culinária para ambos os sexos), embora tivesse conduzido a alguns empregos provisórios. As ofertas no campo da formação profissional exibiam, no entanto, uma notável indiferença pela atividade que os ciganos davam mostras de desempenhar com mais gosto e que, de resto, lhes permitia um contacto com o mundo dos senhores sem se comprometerem demasiado com as suas regras e protegendo-os, inclusivamente, das manobras segregadoras dos empregadores - falamos, é claro, da venda ambulante.

A indiferença pela venda ambulante como modo de vida e de integração na sociedade envolvente tem caracterizado boa parte da intervenção social direcionada para a população cigana desde os anos 1970, aliada a visões pouco sustentadas de decadência da atividade que muitas vezes contrastam com uma hipervalorização dos rendimentos não declarados obtidos por essa via (cf. Branco, 2003). A dificuldade sentida pelos técnicos em enquadrar burocrática e fiscalmente a venda ambulante leva-os muitas vezes a considerar os empregos convencionais como a única saída profissional aceitável (cientes disto, os ciganos muitas vezes corroboram esta visão diante de interlocutores 
não-ciganos, adaptando o seu discurso de modo a poderem continuar a receber determinados apoios). Ora, é indiscutível que as condições para o exercício da venda ambulante se tornaram mais restritas durante o período 2003-2005, mercê do aumento das rusgas policiais e do traslado de antigos mercados de rua para pavilhões cobertos e com uma delimitação mais rígida dos lugares de venda (vide Lopes, 2006). Mas a verdade é que, apesar das crescentes dificuldades, boa parte das famílias ciganas do bairro em causa se mantinham ligadas a atividades de venda ambulante, na sua maioria clandestinas, com as quais complementavam a prestação do Rendimento Mínimo Garantido.

Ao contrário do emprego, um campo em que a inserção dos ciganos no meio envolvente se tornava tão visível e clara como na educação pré-escolar era o da medicalização. No período 2003-2005, a esmagadora maioria dos agregados estavam efetivamente inscritos no centro de saúde da área e possuíam um médico de família. Tal ficou a dever-se, novamente, à implementação do Rendimento Social de Inserção, que incluía a inscrição no centro de saúde da área na lista de contrapartidas que os beneficiários deviam cumprir. Ao mesmo tempo, e em articulação com esta medida de proteção social, um projeto de intervenção comunitária levado a cabo pela Junta de Freguesia revelou-se bastante bem sucedido na promoção de campanhas de vacinação e higiene oral. As mulheres ciganas aceitavam tranquilamente a medicalização da gravidez e do parto, assim como o acompanhamento dos primeiros anos de vida das suas crianças por profissionais do centro de saúde da área. O mesmo começava a notar-se a respeito do controlo da natalidade - uma prática que entretanto se tornou corriqueira. Em situação de emergência, recorria-se às urgências dos hospitais — incluindo o Hospital Dona Estefânia, especializado em pediatria, onde aliás viria a trabalhar um indivíduo cigano como mediador.

É verdade que muitos ciganos pareciam ter uma postura de resistência em relação ao que se chama de medicina preventiva, evitando as consultas de rotina durante a vida adulta e esperando pelo agravamento dos sintomas para reconhecer a necessidade de ir ao médico ou ao serviço de urgência (de resto, sob este aspeto, como tantos não-ciganos). De igual modo, era costume pensar-se que as dinâmicas da saúde e da doença eram regidas por forças sobrenaturais (Deus e o Demónio), sendo frequente o recurso a pastores evangélicos com fama de milagreiros e propiciadores de curas por intercessão. No entanto, tudo isto era perfeitamente conjugável com a medicalização: os enfermos visitavam e seguiam as indicações dos médicos, complementando-as com a intervenção espiritual — uma vez mais, à semelhança de muitos nãociganos. Por fim, refira-se que o próprio internamento hospitalar não colocava aos indivíduos ciganos (especialmente às mulheres) as mesmas ansiedades relativas à observação das distâncias entre os géneros que a escola ou o local de trabalho. Isto porque, à semelhança da prisão — outra instituição nãopoluidora em termos de identidade — , alguns hospitais ainda formalizam a 
separação física entre os géneros com a criação de alas ou quartos separados para pacientes masculinos e femininos, salvaguardando assim a reputação moral das mulheres ciganas.

\section{A escola em 2014-2015: persistência dos problemas, desalento e discriminação}

Os dados mais recentes de que dispomos — os quais dizem sobretudo respeito à escolarização mas que abordam também, de forma parcial, questões relativas ao emprego —, dão-nos a impressão de que as mudanças não foram significativas ao longo dos últimos dez anos, particularmente quando comparadas com o que sucedeu com a restante população. À semelhança de há uma década atrás, a frequência escolar dos alunos ciganos continua a ser mais assídua no primeiro ciclo e muitos pais aprovam a integração dos seus filhos no sistema de ensino desde o pré-escolar. É de registar uma diminuição importante do absentismo no primeiro ciclo, que veio a possibilitar que um maior número de crianças ciganas transitasse para o ciclo seguinte e passasse a frequentar escolas com caraterísticas diferentes das primeiras em termos, por exemplo, de dimensão, organização, diversidade populacional e distância em relação ao bairro, com mais recursos e até mais vontade de receber estes alunos. No entanto, embora cada vez mais alunos ciganos alcancem o segundo ciclo, a maioria não conclui este nível de escolaridade ou completa-o já com algum atraso. A partir do segundo ciclo quase todos os alunos ciganos estão integrados num percurso escolar alternativo, numa tentativa de prolongar o mais possível a sua experiência educativa. A verdade é que esta transição trouxe alguma liberdade aos jovens ciganos, nomeadamente às raparigas e, também por isso, renovou alguns desafios. No entanto, mais de uma década depois, no bairro em questão, os ciganos com o nono ano ou acima disso continuam a constituir uma exceção: registe-se o caso de uma jovem que concluiu o $12^{\circ}$ ano e que tem trabalhado no ramo hoteleiro e da restauração, vivendo maritalmente com um não-cigano de ascendência cabo-verdiana (antigo colega de escola) e, como o seu próprio pai nos contou, levando "uma vida diferente» («não se veste à cigana»).

É verdade que os ciganos dão hoje mostras de atribuir alguma importância aos estudos dos seus filhos, sobretudo no caso dos rapazes, associando-os à possibilidade de obtenção de empregos com um ordenado fixo que lhes permita fazer face às despesas regulares (renda, água e eletricidade). Até que ponto podemos considerar que se trata de uma visão genuína e não induzida pelo contacto com os assistentes sociais e técnicos do Rendimento Social de Inserção é algo mais difícil de aferir. As pessoas que entrevistámos individualmente e os participantes no grupo focal aludem a histórias de gente que estudou e, no final, ficou a varrer as ruas; e invocam a condição 
de cigano como uma desvantagem no acesso ao mercado de trabalho, mesmo para quem tenha estudos. A ligação entre a educação e o emprego é, portanto, ainda algo vaga, como evidenciado a propósito de outros contextos ciganos nacionais e internacionais (Montenegro, 2012; Higgins \& Brüggemann, 2014), e claramente insuficiente para se sobrepor a imperativos locais ligados à identidade cigana, como é o caso do casamento, que continua a ser apontado pelos próprios pais ciganos como uma das razões para o abandono escolar após os treze-quinze anos, sendo poucas as raparigas que continuam a ir à escola a partir do momento em que se juntam.

O trabalho de campo permitiu perceber mesmo assim a existência de um convívio mais solto entre rapazes e raparigas (ciganos ou não-ciganos) em torno do espaço escolar. Os depoimentos de alguns pais corroboram esta ideia, que tanto poderá indiciar uma ligeira mudança face a padrões de comportamento ainda muito marcados pelo evitamento entre os géneros como reforçar a impressão de que a infância continua a ser o período do ciclo de vida em que os indivíduos ciganos usufruem efetivamente de uma maior liberdade de interação com o meio exterior. As alusões a eventuais alterações no campo dos costumes não permitem grandes conclusões em relação a este ponto, dado tratar-se de um argumento tipificado que já circulava pelo bairro em 20032005 (vide Lopes, 2010).

Estas observações, que pretendem caracterizar o ponto de vista dos ciganos, serão agora complementadas com dados relativos às condições oferecidas pelas escolas locais de acordo com as políticas de educação vigentes e com a perspetiva dos próprios professores, no sentido de se encontrar mais pistas para a estagnação.

Ora, no tocante às condições do ambiente escolar, elas mantêm-se pouco atraentes para os alunos ciganos. As escolas do bairro afiguram-se, hoje talvez mais do que há dez anos, territórios de discriminação. Sob este aspeto, vale a pena salientar a implementação recente de processos de hierarquização das escolas em função dos resultados dos exames de transição de ciclo (rankings) que muito provavelmente estarão a levar à adoção de processos de regulação interna conducentes a uma segregação efetiva de alunos menos capacitados e originários de meios desfavorecidos (ciganos ou não-ciganos), os quais deixam de ser objecto de uma atenção mais motivada. Surgem assim recintos escolares proscritos, objecto de intervenção especial por via do programa Territórios Educativos de Intervenção Prioritária (TEIP) e de medidas como os Percursos Curriculares Alternativos (PCA), os Programas Integrados de Educação e Formação (PIEF), e, mais recentemente, o Ensino Vocacional (projeto entretanto suspenso), que se sobrepõem a medidas mais antigas. É justamente este o cenário que encontramos nas escolas do bairro lisboeta aqui em causa. Em 2003-2005, as mesmas escolas contavam com o auxílio de Gabinetes de Apoio ao Aluno e à Família (GAAF) e de mediadores ciganos, cujo trabalho, 
como se disse, era difícil mas contribuía para a aproximação mútua entre os alunos ciganos e o ambiente escolar. Em 2014-2015, os Gabinetes de Apoio ao Aluno e à Família mantinham-se mas os mediadores estavam ausentes e muitos pais ciganos lamentavam-no, reconhecendo que os mediadores sempre vigiavam as crianças nos passeios, visitavam os familiares em caso de absentismo, evitavam brigas nas escolas e faziam a ligação com os professores quando estes se mostravam mais alheios aos alunos ciganos. Fica pois a ideia de que os mediadores compreenderiam melhor as ansiedades sentidas pelos pais ciganos que eram obrigados a deixar as suas crianças num espaço desconhecido, pouco acessível, potencialmente promíscuo e discriminatório. Mais uma vez, o reconhecimento da figura do mediador por parte das instituições não-ciganas não coincide com o ponto de vista cigano, reduzindo-se a importância da sua intervenção praticamente à resolução de eventuais conflitos entre a escola e as famílias.

O facto de as escolas deste bairro fazerem hoje parte de um Território Educativo de Intervenção Prioritária (TEIP) não parece ter contribuído significativamente para atenuar a situação, exceto no que diz respeito aos alunos ciganos inscritos nos Percursos Curriculares Alternativos (PCA), os quais beneficiavam de um acompanhamento mais atento e que se traduzia numa maior assiduidade. Mas tratava-se de uma medida de recurso criada após não aprovação, por parte do Ministério da Educação, da proposta de formação de turmas PIEF apresentada pelo agrupamento, tendo em conta a necessidade de voltar a integrar um conjunto de alunos, na sua larga maioria ciganos, no sistema de ensino. O caminho futuro destes alunos afigurava-se, portanto, incerto: se é verdade que eles beneficiavam de uma maior atenção, deve dizer-se que a generalidade dos professores não depositava grandes expetativas nestes seus alunos. De resto, as condições postas à disposição das escolas estariam aquém do exigido para um Território Educativo de Intervenção Prioritária: havia algum apoio psicológico e assistencial (proveniente do velho Gabinete de Apoio ao Aluno e à Família), mas as características dos alunos de primeiro ciclo justificariam a existência de dois professores por turma, o que não se verificava em caso algum e não deixa de ser irónico, dado que a duplicação dos professores poderia ter um impacto positivo em termos do sucesso do percurso escolar dos alunos ciganos.

Como que a atestar a ideia de uma distância persistente entre a escola e os ciganos, a nota dominante deixada pelos professores participantes no grupo focal realizado foi de frustração. Estes professores referiram que a assiduidade dos alunos ciganos era reduzida e frequentemente acompanhada por faltas de material, de pouco adiantando chamar a atenção dos pais para este facto. A frustração dos docentes tornava-os naturalmente mais recetivos a estereótipos que associam os pais ciganos a ameaças e agressões e que encontram o seu fundamento, muito provavelmente, em determinados episódios noticiados 
pelos media. Um professor e diretor de turma que colaborou num grupo focal realizado em 2014 foi ao ponto de referir que os ciganos exemplificavam uma situação de abandono escolar que ocorria dentro da própria escola, à qual compareciam sem material, apenas para almoçar e para que os pais não perdessem o direito à prestação social (o mesmo podendo ser dito a respeito de outros beneficiários do Rendimento Social de Inserção):

[E]les não vem aquifazernada.(...) Esta escolaridade que supostamente eles têm não é escolaridade, porque a escolaridade implica trabalho, implica responsabilidade, implica cumprir objetivos. Portanto se eles vierem aqui numa situação de "eu tenho que ir à escola...". Aliás, o que eles dizem-me a mim... são putos de 12 anos?! Já me responderam assim: "Professor, professor eu só venho à escola porque perco o subsídio»

Trata-se, é certo, de uma opinião pessoal, de resto nem sempre acompanhada por outros docentes participantes no mesmo grupo focal. Mas ela ilustra o desânimo sentido por muitos professores relativamente aos seus alunos ciganos e o modo como esse desânimo alimenta a reprodução dos preconceitos. De forma indireta, mas não menos significativa, esta opinião epitomiza o conflito de perspetivas sobre a integração a que aludimos na introdução deste artigo. Num tal cenário, não é de estranhar que nos tenham sido relatadas situações de discriminação num dos Agrupamentos Escolares que servem esta freguesia de Lisboa (por exemplo: isolamento e segregação dos alunos ciganos, faltas por atraso marcadas a alunos ciganos e retiradas a alunos não-ciganos...). Daí que, por não se sentirem bem e por não existirem muitas alternativas em termos de continuidade dos percursos escolares, muitas famílias ciganas tentassem inscrever as suas crianças no agrupamento que lhes oferecia maior segurança, nomeadamente a partir do $2^{\circ}$ ciclo.

\section{0 acesso ao emprego nos dias de hoje: ponto de situação}

No tocante ao acesso ao mercado de trabalho, a impressão de estagnação mantém-se com a agravante de que a situação de crise se acentuou a partir de 2008, fazendo com que as oportunidades de emprego se tornassem ainda menos numerosas e atraentes. Acresce que a exclusão económica é quase sempre acompanhada por discriminações de género, raça ou etnia, não sendo portanto de estranhar que os ciganos continuem a queixar-se de dificuldades no acesso a empregos, circulando várias histórias que associam a revelação da pertença étnica a uma maior probabilidade de recusa ou dispensa por parte dos patrões, independentemente das habilitações escolares do candidato.

Como se disse na introdução deste artigo, uma parte substancial dos agregados do bairro subsiste com base no Rendimento Social de Inserção, 
complementado com os ganhos adicionais proporcionados por biscates e pela prática clandestina da venda ambulante, de ganhos incertos em virtude da redução generalizada do poder de compra após a introdução da moeda única, do aumento da perseguição policial aos vendedores clandestinos e, ainda, da necessidade de cumprir com determinados requisitos associados ao Rendimento Social de Inserção (por exemplo, a frequência de cursos de formação que roubam tempo e têm pouca utilidade). Nas palavras de um vendedor ambulante de 50 anos entrevistado em 2014:

[Antes,] a gente ia para uma praça ou para uma rua, deixavam trabalhar mais à vontade, a gente ganhava para sobreviver. (...) [Antes do euro,] a gente, naquela época, iamos para uma rua, íamos com umas calças ou umas coisas assim, vendiamos e trazia-se dinheiro.

O trabalho de campo realizado em 2014-2015 permitiu-nos ainda constatar que muitas famílias ciganas perdiam facilmente o direito ao Rendimento Social de Inserção, fosse por incumprimento do programa contratualizado ou por questões administrativas (falta de documentação, etc.). Para mais, os contactos com a Segurança Social por parte das pessoas afetadas pela perda do subsídio eram particularmente complicados. Por alguma razão, parecia ser impossível ligar para estas assistentes por via de projetos e instituições locais - dizia-se que era porque as mesmas assistentes reconheciam o número de onde provinha a chamada e raramente atendiam - o que obrigava os beneficiários ciganos a usarem os seus telemóveis. Como se pode calcular, a perda do direito à prestação fez com que muitos ciganos tentassem sobreviver por outras vias, nomeadamente retomando a sua atividade feirante. Perante a impossibilidade de acederem a mercadoria variada e aos lugares de venda que antes detinham, alguns deles acabaram por concentrar-se na venda clandestina - que parece ter sido a principal alternativa ao Rendimento Social de Inserção —, resvalando assim para uma solução ainda mais precária que a anterior.

Não deixa de ser interessante notar como, apesar de todas as dificuldades que rodeiam a sua prática, a venda ambulante se mantém um recurso estimado e criativamente recriado pelos ciganos (vide Brazzabeni et al. 2015), uma vez que as alternativas disponíveis são escassas e igualmente pouco compensadoras: não é, de facto, claro que os jovens ciganos com mais escolaridade tenham facilidade em aceder a empregos que considerem razoáveis e essa possibilidade torna-se ainda mais remota no caso de adultos com alguma idade. Vale a pena sublinhar que mesmo os indivíduos que trabalham por conta de outrem e auferem um salário fixo gostam de fazer feiras aos fins-de-semana, não só para poderem beneficiar de um rendimento extra como também para conviverem com outros ciganos. As razões de identidade têm obviamente importância nas escolhas económicas dos membros desta comunidade. 


\section{Conclusão}

Iniciámos este artigo com uma reflexão acerca da integração dos ciganos que chamava a atenção para as duas faces do problema (a cigana e a não-cigana) e para a manifesta desproporção patente ao nível da sua resolução que faz com que a perspetiva não-cigana pressione as comunidades ciganas sem nunca chegar a ser pressionada por elas. Procurámos equilibrar um pouco os pratos da balança e atribuir ao ponto de vista cigano uma legitimidade equiparável à dos senhores e doutores, o que implica deixar de olhar para a escolarização e para o emprego como bens indiscutíveis e forçosamente desejáveis mas sim como premissas decorrentes de um universo institucional que circunda as comunidades ciganas e ao qual estas têm de se adaptar, num movimento que pode ter tanto de oportuno e emancipatório como de opressivo e limitador. Nesta base, comparámos os dados relativos à educação e ao emprego para um mesmo bairro lisboeta em períodos diferentes, tendo verificado que a impressão dominante é, no essencial, uma impressão de estagnação. O que dificilmente surpreenderá alguém e lembrará muitos outros contextos com características similares. Por isso mesmo, vale a pena concluir com uma reflexão mais incisiva sobre as razões que poderão justificar uma tal situação, sem cairmos na tentação de argumentos circulares e explicações simplistas assentes no racismo e na ciganofobia (que existem, bem entendido, mas não são necessariamente a causa dos problemas aqui identificados).

No que tange à escolarização, a primeira observação que deve ser feita tem a ver com o significativo desinvestimento no sistema público de ensino verificado ao longo da última década, que contribuiu para acentuar uma divisão entre escolas protegidas e escolas proscritas de índole mais propriamente socioeconómica do que étnica (embora refletindo-se também neste plano). É nas escolas proscritas que encontramos os alunos ciganos, a par de muitos outros alunos provenientes de meios desfavorecidos e de uns tantos professores com vínculos precários fazendo pela vida e ansiando por colocações mais propícias. Se é verdade que medidas como os Percursos Curriculares Alternativos e os Programas Integrados de Educação e Formação permitiram o prolongamento da permanência na escola e mesmo a continuidade do percurso escolar de muitos jovens ciganos (rapazes e raparigas) do bairro aqui em causa, levando-os a concluírem o segundo ciclo e até mesmo o terceiro ciclo, ainda será cedo para se perceber até que ponto a escolarização é efetivamente integrada nos projetos de vida dos indivíduos ciganos como algo mais do que uma contrapartida pelo acesso a outros apoios.

Olhando com mais atenção para o que se passa no interior das escolas proscritas e que acumulam medidas de recurso, verificamos que a maioria dos ciganos se encontram integrados em turmas especiais, compostas por alunos com piores resultados, relativamente às quais os professores admitem sentir enormes dificuldades. A segregação desdobra-se, portanto, e faz com que a 
motivação e as expectativas sejam baixíssimas, tanto da parte dos docentes como dos alunos. A própria falta de estabilidade do corpo docente contribui para agravar este problema, tendo em conta a importância de uma convivência prolongada, assente numa boa preparação e no conhecimento mútuo, para o sucesso do trabalho desenvolvido em conjunto com a população cigana (ao invés, nada melhor que um contacto esporádico para a reprodução de estereótipos e regras discriminatórias...). Em suma, o racismo está presente, mas sobretudo como consequência da progressiva deterioração do sistema público de ensino, e das carreiras a ele associadas, numa época marcada pelo controlo apertado das despesas do Estado e pelas políticas de austeridade.

Vale a pena sublinhar, ainda a respeito da educação, a inexistência de estratégias de acompanhamento dos alunos após a frequência escolar e formativa, de modo a avaliar os impactos reais das estratégias e opções seguidas. Assim, mais do que facilitar o acesso a uma integração profissional que respeite os princípios da identidade cigana e seja suficientemente compensadora em termos económicos, a grande preocupação das escolas passa por assegurar que estes alunos permaneçam o máximo de tempo possível dentro do sistema de ensino, de modo a aprenderem o que muitas vezes se chama de «regras básicas» (como se os ciganos proviessem de um qualquer mundo sem regras...) e, na melhor das hipóteses, completarem o terceiro ciclo do ensino obrigatório.

O cenário não é mais animador no que diz respeito às políticas sociais e de emprego que, desde finais dos anos 1990, e ao abrigo da Estratégia Europeia de Emprego, parecem sobretudo interessadas em promover abordagens proativas e responsabilizadoras em detrimento de políticas mais passivas e que serviam tradicionalmente de amparo em situações de dificuldade (cf. Valadas, 2012). Os centros de emprego debatem-se com limitações consideráveis ao nível dos recursos humanos, parecendo incapazes de responder eficazmente aos jovens ciganos que procuram trabalho - aliás como aos desempregados de longa duração ou com mais de cinquenta anos e a outros grupos economicamente excluídos, independentemente da relevância da pertença étnica. A isto deve ser acrescentado o caráter punitivo das políticas sociais, que reduz a viabilidade de um percurso profissional autónomo desenhado pelos beneficiários e integrado nos seus projetos de vida, percurso esse que se vê confrontado, no caso particular dos ciganos, com a tradicional desconfiança de técnicos e assistentes sociais face à venda ambulante e outras atividades lucrativas que não encaixam numa conceção marcadamente etnocêntrica de trabalho.

Tudo isto decorre, e também acentua, a falta de convergência entre as duas perspetivas sobre a integração cigana a que fizemos referência na introdução deste artigo: a perspetiva dos ciganos propriamente ditos e a perspetiva institucional dos não-ciganos ou senhores. Ora, o diálogo com as diversas comunidades ciganas exige paciência e determinação, sendo que o mesmo corre o risco de ser interrompido e substituído pela repressão. Neste sentido, importa 
continuar a refletir sobre a flexibilização dos meios de acesso à escola e das próprias estratégias de ensino, tendo em conta experiências inovadoras que incluem o ensino à distância, os programas formativos adaptados ou as escolas de segunda oportunidade. Só assim os ciganos poderão encarar a escola como algo mais do que uma obrigação sem sentido e uma ameaça àquilo que, nas circunstâncias atuais, surge como a sua identidade coletiva.

\section{Menção de Apolo}

O trabalho de investigação necessário à elaboração deste artigo foi feito ao abrigo dos projetos UID/SOC/04521/2013 e Factores-chave para o Sucesso e a Continuidade dos Percursos Escolares dos Ciganos: Indivíduos, Famílias e Políticas Públicas (PTDC/IVC-PEC/4909/2012), ambos financiados pela Fundação para a Ciência e a Tecnologia (FCT), tendo também contado com o apoio financeiro de uma bolsa de doutoramento (SFRH/BD/10459/2002) e de uma bolsa de pós-doutoramento (SFRH/BPD/78438/2011) atribuídas pela mesma fundação.

\section{Referências}

ABAJO, José Eugenio e Carrasco, Sílvia (org.) (2004), Experiencias y trayectórias de éxito escolar de gitanas e gitanos en España: Encrucijadas sobre educación, género y cambio cultural, Madrid: CIDE/Instituto de la Mujer.

ARDÈVOL, Elisenda (1986), "Vigências y cambio en la cultura de los Gitanos", in Teresa San Román (org.), Entre la Marginación y el Racismo: Reflexiones sobre la Vida de los Gitanos, Madrid, Alianza Editorial, 61-108.

APPADURAI, Arjun (1996), Modernity at Large: Cultural Dimensions of Globalization, Londres, University of Minnesota Press.

BLASCO, Paloma Gay y (1999), Gypsies in Madrid: Sex, Gender and the Performance of Identity, Oxford, Berg.

BRANCO, Francisco José do Nascimento (2003), “Os ciganos e o RMG: Direitos sociais e direito à diferença”, Intervenção Social, vol. 27, 21-143.

BRAZZABENI, Micol, Cunha, Manuela Ivone e Fotta, Martin (2015), "Introduction: Gypsy Economy”, in Micol Brazzabeni, Manuela Ivone Cunha e Martin Fotta (org.), Gypsy Economy: Romani Livelihoods and Notions of Worth in the 21st Century, New York, Berghahn Books, 1-29.

BRÜGGEMANN, Christian (2014), "Romani culture and academic success: arguments against the belief in a contradiction”, Intercultural Education, vol. 25(6), 439-452.

CASA-NOVA, Maria José (2009), Etnografia e produção de conhecimento: reflexões críticas a partir de uma investigação com ciganos portugueses, Lisboa, Alto Comissariado para a Imigração e Diálogo Intercultural (ACIDI).

COMISSÃO EUROPEIA (2010), Comunicação da Comissão ao Conselho, ao Parlamento Europeu, ao Comité Económico e Social Europeu e ao Comité das Regiões: A Integração Social e Económica dos Ciganos na Europa, disponível em: http://eur-lex.europa.eu/ 
legal-content/PT/TXT/PDF/?uri=CELEX:52010DC0133\&from=EN [Consultado em 15 de Julho de 2016]

COMISSÃO NACIONAL DO RENDIMENTO MÍNIMO (2002), Avaliação de Impactes do Rendimento Mínimo Garantido: Caracterização dos Perfis dos Beneficiários RMG Minorias Étnicas, Lisboa, Instituto para o Desenvolvimento Social.

COUNCIL OF EUROPE (2012), Human Rights of Roma and Travelers in Europe, Estrasburgo, Council of Europe Publications. [Disponível em: https://www.coe.int/t/commissioner/source/ prems/prems79611_GBR_CouvHumanRightsOfRoma_WEB.pdf [Consultado em 15 de Julho de 2016]]

Estratégia Nacional para a Integração das Comunidades Ciganas: 2013-2020 (2013), Lisboa, ACIDI.

GMELCH, Sharon Bohn (1986), “Groups that don't want in: Gypsies and other artisan, trader, and entertainer minorities", Annual Review of Anthropology, Vol. 15, 307-330.

GOMES, Maria do Carmo (2013), "Políticas públicas de qualificação de adultos e comunidades ciganas: movimentos inclusivos", in Maria Manuela Mendes e Olga Magano (org.), Ciganos Portugueses: Olhares Plurais e Novos Desafios numa Sociedade em Transição, Lisboa, Mundos Sociais, 81-91.

HIGGINS, Niall e Brüggemann, Christian (2014), "The Consequences of Cumulative Discrimination: How Special Schooling Influences Employment and Wages of Roma in the Czech Republic”. European Educational Research Journal, Vol. 13(3), 282-294.

LOPES, Daniel Seabra (2006), "Mercados encobertos: os cigBrueanos de Lisboa e a venda ambulante”, Etnográfica, Vol. 10 (2), 319-336.

LOPES, Daniel Seabra (2008), Deriva Cigana: Um Estudo Etnográfico sobre os Ciganos de Lisboa, Lisboa, Imprensa de Ciências Sociais.

LOPES, Daniel Seabra (2010), "Retrospective and prospective forms of ritual: suggestions of social transformation in a Portuguese Gypsy community", Anthropological Quarterly, Vol. 83 (4), 721-751.

LOPES, Daniel Seabra (2013), "Introversão e derivas: ao encontro dos ciganos de Lisboa", in Maria Manuela Mendes e Olga Magano (org.), Ciganos Portugueses: Olhares Plurais e Novos Desafios numa Sociedade em Transição, Lisboa, Mundos Sociais, 175-189.

MENDES, Maria Manuela, Magano, Olga e Candeias, Pedro (2014), Estudo Nacional sobre as Comunidades Ciganas, Lisboa, Alto Comissariado para as Migrações.

MONTENEGRO, Mirna (2012), Aprender a ser cigano, hoje: empurrando e puxando fronteiras. Tese de doutoramento em educação, Lisboa, Universidade de Lisboa - Instituto de Educação.

NICOLAU, Lourdes (2010), Ciganos e Não-ciganos em Trás-os-Montes: Investigação de um Impasse Interétnico, tese de doutoramento em Ciências Sociais, Chaves, Universidade de Trás-os-Montes e Alto Douro.

NICOLAU, Lourdes (2013), "A população cigana do Nordeste Transmontano: dinâmicas diversificadas em meio urbano e rural”, in Maria Manuela Mendes e Olga Magano (org.), Ciganos Portugueses: Olhares Plurais e Novos Desafios numa Sociedade em Transição, Lisboa, Mundos Sociais, 207-221.

PARLAMENTO EUROPEU (2012), "Estratégia da UE para a integração dos ciganos”, Jornal Oficial da União Europeia, C 199 E, 112-131.

PASQUALINO, Caterina (1999), "Hors la loi: les Tsiganes d'Europe face aux institutions", Ethnologie française, Vol. 29 (4), 617-626.

VALADAS, Carla (2012), "Políticas públicas para o emprego em Portugal: de acção reguladora a potencial emancipatório?”, Configurações, 10: 83-94. 
